\title{
EVOCATION OF THE HEAD AND BRAIN IN OLD VAULTED BUILDINGS*
}

\author{
C. LEWIS KAUSEL \\ Mount Ida College, Newton, MA, USA.
}

\begin{abstract}
This article explores some analogies in form that may exist between the human shape - especially the head and upper torso, and also including the brain - and architectural elements found in old historic, vaulted buildings. The plausibility of these analogies is supported herein mainly with the aid of original drawings by the author and relies on the visual logic of elements in the language of design rather than the abstract methods of science. Thus, the conjectured interpretations illustrated in this article are meant as visions of an artist working at the boundaries between art and architectural design, rather than as incontrovertible principles of engineering science. Admittedly, the parallels that we claim are observable in vaulted spaces may not necessarily be obvious to all readers, and it is also clear to us that the analogy, however repetitive, does not have a universal expression in space and time. Still, within the domain of applicability to old historic buildings considered in this essay, the interpretations advanced herein are likely to interest readers with keen artistic sensitivity, and also shed some light into the creation of constructed artifacts and their assimilation by the cultural psyche.

Keywords: fundamental aesthetic image, human brain morphology in design, nature's shelter.
\end{abstract}

\section{INTRODUCTION}

Three decades ago, the author observed that many architectural forms and artifacts of the past, especially medieval vaults, arched doorways and windows, can exhibit in their elevation noticeable similarities in decoration or outline to the brain, or the head on the shoulders, which she then explored further in a graduate thesis [1]. This realization motivated the creation of a number of original drawings - some with visionary characteristics - illustrating these parallels, a selection of which is included in this article to exemplify these observations. Conceivably, when designers created these structural forms, their imagination must have reached deep into the collective sub-conscious and arrived at most of such human-like designs intuitively. While the evocation of the human form in the shaping and decoration of vaults may be subtle and by no means immediately obvious to a casual observer, it can certainly be distinguished, as it will be graphically illustrated herein together with an attempt to discern some possible underlying reasons.

\section{DESIGN AS ULTIMATELY JUDGED BY INDEPENDENT OBSERVERS}

In a way, the history of constructed things reflects the intellectual development of mankind. This development has, on the one hand, the dimension concerned with the creation and perfecting of technology (science), and on the other, the utilization of built artifacts, including their stylization, decoration and refinement. Indeed, artifacts can communicate some notions, such as the period when something was designed or how the culture used it. Among the least understood questions is the issue of how a culture becomes attached to objects, and how the visible attributes of constructed and manufactured things communicate qualities and even symbolic recollections which cause people to hold them in esteem.

*Paper submitted for publication August 2006.

(C) 2007 WIT Press, www.witpress.com

ISSN: 1744-3687 (paper format), ISSN: 1744-3679 (online), http://journals.witpress.com DOI: $10.2495 / \mathrm{D} \& N-\mathrm{V} 2-\mathrm{N} 3-258-276$ 
Before elaborating further on the similarities between inner architectural spaces and the upper part of the body alluded to previously, we begin by briefly summarizing essential definitions and concepts of the subject matter at hand that can reflect the way in which common observers assimilate buildings and other designed artifacts.

Architectural design in general, and the design of inner spaces, such as vaults and arches in particular, is mainly governed by key aspects, such as the conceptual design, the methods used, and the materials. Furthermore, the perception by external observers of the multifaceted qualities of an architectural work, and the complex personal emotions that it may elicit in the public at large after its completion - something that could be referred to as the outcome - is profoundly influenced by the combination of such key elements working in tandem. In brief, they are:

1. Conceptual design. It is the design composition that defines what structural forms and shapes best serve the function and objectives sought, both immediate (purpose and usage of building) as well as removed (character, harmony with the surrounding physical environment, size and style of nearby structures, access roads, etc.). Conceptual design will also decide on detailing, surface treatments, and adornments if desired, such as vitreuse, wall coverings, frescoes, paintings, gargoyles, and so forth. In its most elevated and refined form, conceptual design attains the level of fine art and exercises a profound influence on the society at large and vice versa.

2. Method. This includes physical and mechanical principles, technique of construction, constructability of the design; it decides how gravity and other forces can and should be transferred within the structure to its supports. It strongly influences the overall shape of the structure. In particular, arches and domes permit spanning great spaces with relatively brittle materials such as masonry or stones, which they achieve by an ingenious arrangement of stone wedges or voussoirs that are subject to mostly benign compression. This effect is achieved at the expense of having to provide lateral support to the arches by means of other structural elements that resist the lateral thrust, e.g. external buttresses. To minimize weight, ribs were used in vaults and domes, relying on a reticulated design on the interior. Domes could have additional interior coffering which reduces some of the mass giving a graceful and characteristically classical finish to the design.

3. Materials. The choice of materials (wood, stone, masonry, steel, etc.) for some project follows not only from functional considerations, such as strength, stiffness, or geometry (i.e. desired distance between supports), but also from aesthetic goals (suitability of a material to achieve desired qualities, such as sculptural, textural, transparency, etc.). These in turn have a strong influence on the visual attributes of design and the expression and success of the resulting structure or interior, i.e. on the outcome.

According to Gottfried Semper, a notable theorist of the 19th century, architectural adornment is pre-eminent [2] over methods and materials on the outcome, while others, especially the Bauhaus' Gropius and Mies van der Rohe, rejected excessive design and ornaments, and believed that form must follow function and that less is more, thus preferring starkly simple forms and unadorned surfaces. Nonetheless, herein we shall not take sides in design values, or attempt to discern which of the three above-mentioned aspects of architectural design, i.e. concept, method, or material, may be the most influential on the outcome, but we will take the holistic view instead that all three participate in some indeterminate proportion, and that the perception and assimilation by society of the completed work may not necessarily correspond to the original intentions and expectations of the designers. External observers tend to perceive the outcome of any design as visual aspects (or looks) and this is society's way of assimilating forms.

To illustrate this concept, consider the case of a portrait photograph, which is a flat entity and simple enough to help us discern some of the above-mentioned relationships. Clearly, upon seeing a 
photograph, we do not simply dissect a portrait's various attributes, noticing a two-dimensional piece of paper with patches of colors and a recognizable figure, but instead react with a range of emotions to the three-dimensional image in the photograph with which we may identify or feel empathy, as if the actual person portrayed were there. It is then the subject of the photograph that we display on a wall or put in an album.

The same is true of music: depending on its mood and context, it may elicit a change of mood in us and certainly very profound emotions, even though we may not be able to play a single instrument or know one line of musical theory. When we listen to music, we most certainly do not appreciate it by its separate, individual components (type and number of instruments, acoustics, etc.) but just simply know if the composition is good and gives us pleasure, and that is enough to make us want to hear the piece again, without the need for rationalization. Furthermore, good music, as all good art, including design, profoundly alters our internal disposition and affects our very perception of other external realities. While the composer (i.e. the designer of the music) uses his/her intellect to craft the piece, the outcome reaches our hearts and souls in both the figurative and literal sense. Furthermore, some of the emotions that the music can elicit in an audience may not be the result of prior deliberate design, but result instead from other subconscious contextual dimensions of the culture, i.e. from the Zeitgeist - the spirit of the times. A comparable integrative process is at work in the outcome of design.

\section{HUMAN OUTLINE}

Figure 1 (Misterium) shows a vault based on the English hammer-beam truss - liberally inspired by Westminster Hall - that is surrounded by a human outline. At the far end of the hall is an interior arched structure that likewise evokes a faint human image. The shapes of the vault and of the smaller trefoil structure strongly evoke the human upper torso's outline. A configuration or organization can be chosen by a designer simply because it came to mind and seems fit, although the configuration may have an association or origin that may be buried in the mind and not be consciously realized. Why the outline of the upper torso? First, the human blueprint is surely well impressed in our intuitive cognition for adaptive reasons and it reflects 'right' attributes and proportions in architecture. (The utilization of body measurements to proportion building parts has been used in classical architectural theory, at least from the treatise of Vitruvius to later writers, especially during the Renaissance.) Also, imagination and empathy interact with intelligence in cognition, especially in the perception of artistic forms. The part of the body that feels is the center of the chest, i.e. the 'heart'. Thus, intellect and feeling, which are intimately tied to the way the human organism perceives, are part of a creative effort. Thus, the outline of head and upper torso achieved using an arcuated arrangement of three arches may be a reflection of a designer's self-image in the space conceived (see Fig. 1). It is not easy to determine what causes this phenomenon, and whether or not it is an integral aspect of the intellect, but our guess is that it is. By this we mean that in the challenging moments of the history of architecture, the search for the elusive answer to the question of what is the best or right design could lead to the choice of this outline, both, as a subconscious 'reply' to the question of what is the right structural form for mankind, and also sometimes as an imprint of the human intellect which has created the structure. Lay persons experiencing the space of a building thus designed also discern clearly an intimate correspondence between the parts, even if they may not necessarily recognize consciously its meaning or even a human outline $[1,3]$.

Second, in the evocation of the human figure, perhaps it is important to consider the way in which we relate to space, and we should entertain the possibility that subconscious configurations and patterns that exist in the cognitive stores can surface out in creativity. It seems natural that a representation of the intellect should appear in the space's ceilings and vaults as in the various parts 


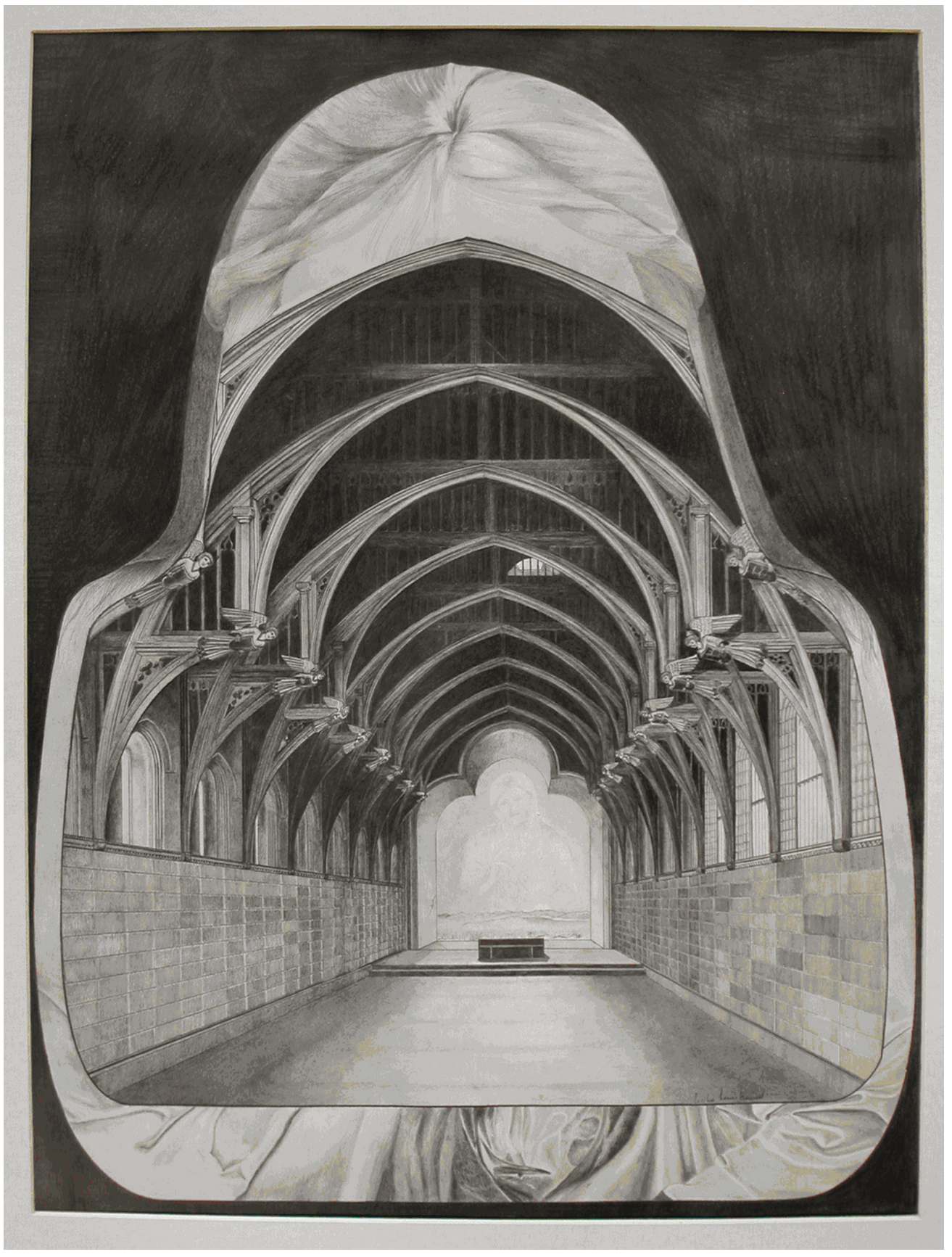

Figure 1: Misterium. Original drawing by Cecilia Lewis Kausel, 1988. 
and organs of the body, intellectual activities, and ideas reside high above. In the distribution of our senses in our vertical posture, all thoughts are 'sensed' as originating somewhere within the head, almost behind the eyes and within the forehead. Then again, a concave space enhances the suitability of the evocation and for a reason, and that is that the head is nearly spherical. The evocation of the head can also be proposed in the coffered vaults of antiquity, such as in ancient classical domes and some smaller funerary structures. The human outline of the head, neck, and torso can also be discerned in Middle Eastern arches and in some domes above a tower.

\section{COVER AND SHELTER}

Buildings of past centuries were often created in the context of religion. (It is widely accepted by authors that the conscious symbolism of history's domes is related to the heavens.) Moreover, religious buildings were often designed to stand as out-of-the-ordinary architecture and in accord with the requirements of a faith, which influenced the symbolism of the structural form, along with other parameters such as liturgical design and requirements for building features. This could provide a substantial source of decorative images in walls and ornaments. Hence, the outline of the head of saints and of the nimbus (or gloria), for example, could have to some extent set a pictorial precedent that influenced the organization of elements in design (e.g. in the early times of the Byzantine, Greek, and Armenian Christianity, where mosaics of saints were used on walls). Especially, the prominent icons decorating domes could have been a precedent that inspired the design of arches or niches with the shape and proportion of the head with a nimbus. (This nimbus shape is observed in painted decorative arches in manuscript illumination as well as in built horse-shoe arches of Spain and France. Yarza [4] proposes a date for this form (painted and built) in late Roman times. Jairazbhoy [5] mentions the presence of horse-shoe arches in Syria from the third century.) However, this origin is not a likely model for other ways in which the human head is evoked in vaults.

In the case of the minor crafts and paintings, as opposed to the structural vaults (Fig. 2), where the sculptures at Chartres Cathedral are sheltered by a miniature building serving as an aedicule, the association of human figure and miniaturized building may have evolved in a conscious manner. Specifically, the architectural forms above the saints could be interpreted as providing spiritual protection. From the fact that a cathedral's sculpture was intended to educate, this miniature architecture certainly had an allegorical meaning such as, for example, Celestial Jerusalem. Clearly, in the sculptures of medieval cathedrals, where ritualized structural shapes followed from both religious architectural parts and from the art of carving, the aediculae seem to have the purpose of indicating a safe haven or spiritual cover over a saint. Because of this, the motif associating miniature vault and human figure, as found in the Middle Ages, could have been consciously sought after by both clergy and craftsmen, if not by the medieval masons themselves. The specific examples shown in Fig. 2 exhibit a single central pointed prominence in the manner of a helmet's nose piece. The carver of that aedicule links the form of the helmet with vaulted spaces, i.e. the tiny vault which shelters the head plays the role of a helmet. (E.B. Smith, in The Dome believes that the helmet of antiquity is important for the development of domes. The presence of votive helmets in ancient Greece speaks of the symbolism of this object).

The one shaped as a pearled crown seems to indicate that the miniature building is like precious shelter above the heads of the saints. It is in these sculptures that show human figures with their own personal vault (scaled aedicules) that one of the most intimate architectural meanings is revealed in the form of a motif with two parts with complementary curvature: vault and human head. This aedicula is like precious shelter above the heads of the saints [1,3]. And it is not necessary to see this consciously - or to reflect much - to be moved by the design synchronization of these covers with the figures of the saints $[1,3]$. 


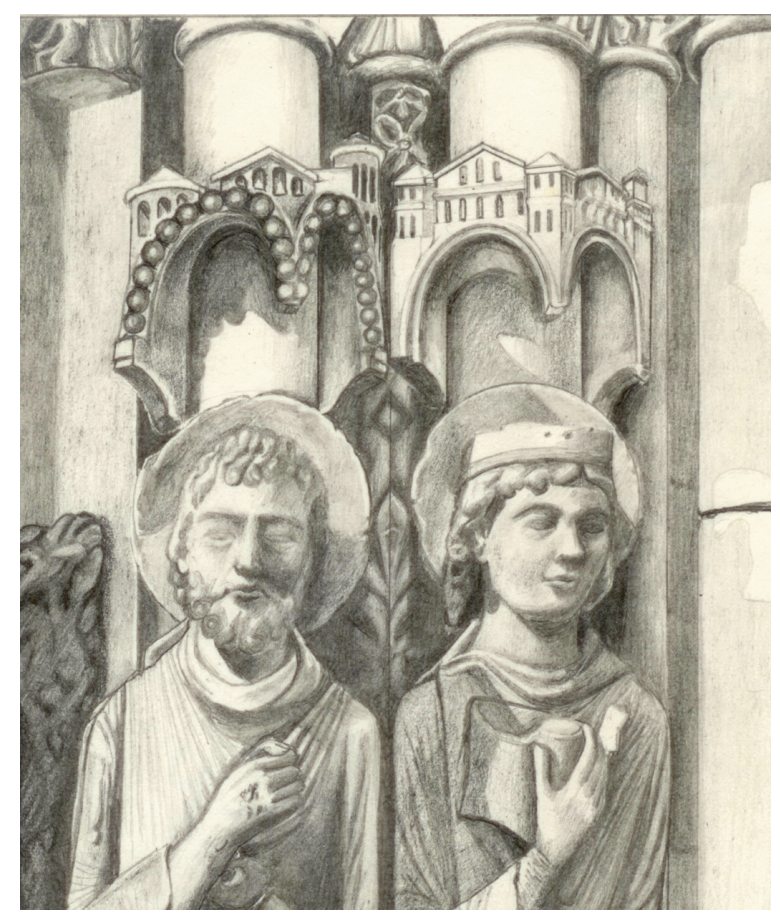

Figure 2: Biblical personages in the Royal Portal of Chartres Cathedral, mid-12th century. Drawing by Cecilia Lewis Kausel, 1982.

While making observations of this kind, one may inevitably wonder if the evocation of the head and the shoulders in structural vaults - as opposed to that in minor crafts - was a case of subliminal design, or instead the result of a deliberate and intended process, however subtle, on the part of the masons. It could be argued that the latter possibility is unlikely in the case of full-scale vaults. For one thing, the difference in scale is substantial, but more importantly, the evocation of the human form's outline is strongly recognizable in the decorative vaults and doorways of medieval mosques, where doctrine proscribed the explicit depiction of human images. Since the 13th and 14th centuries, this proscription extended to all human-like images ([5] p. 9). Therefore, if Islam's builders of mosques had noticed a human origin or a figure with nimbus in their horseshoe arches, they would have avoided it. And yet it is indeed interesting, that something as strong as faith-based proscription did not preclude the human form from appearing in the design of Islamic vaults and doorways, because it supports a notion that such recollection was not realized, or was forgotten at the time, and had its continuity because of subconscious, subliminal processes.

In recent years, the human form has been celebrated in other architectural contexts by the contemporary engineer and architect Santiago Calatrava. He is known to have inspired explicitly some of his modern designs on the shape of human body parts, such as the fingers, the arms, the eye, and the legs, focusing on how nature carries and resists forces within bodies, and also for purely aesthetic reasons [6]. By contrast, the type of parallel between human form and vaults that we have explored and present herein obeys not a search for the structural function of natural forms, but it expresses instead an innate need for shelter that is characteristic of the human soul. 
Other alternative interpretations and parallels between nature and man-made objects can also be found in recent works by Portoghesi [7] and by Burgess and King [8]. In his voluminous and richly illustrated book, Portoghesi provides abundant examples of parallels between architecture and nature, including some related to the human skeleton and the body's nerves, although not quite along the lines of what we have explored and are propounding herein. On the other hand, Burgess and King allude to the strong analogies in the shapes and styling of modern automobiles with the human face, as well as with animal forms. This deliberate, utilitarian goal seeks to tap into the subliminal cognition of the car buyers, who will feel attracted to the gracefulness of an idealized impala or the beauty of a woman's face.

The evocation of the human figure in buildings alluded to previously, presents an interesting analogy to nature, that is, the way that some structural forms of nature are found in relation to a creature they house. The logic behind the analogy is something like this: some animals have their own naturemade shell or exoskeleton that fits their bodies and provides them protection. Thus, if the human species had its natural cover, it would logically have followed the form of the human figure. Perhaps the lack of natural protection and the vulnerability of the human creature further intensify the depiction of some appropriate human-like shelter in architectural design. Some motifs seem to have been shaped to evoke this analogy, such as a scalloped niche in association with a sculpture. Likewise, the distortion of arches in miniaturized representation, so as to echo more closely the outline of a human figure, speaks about this analogy (see Figs 3 and 4).

Figure 3 depicts King David, which is inspired by a sculpture of Benedetto Antelami at the Fidenza Cathedral in Italy. In the miniature vault's intrados above the king's head, one can see the Holy Family crowned by aediculae whose contour and lack of vertical plumb closely follow the shapes of the human figures there. Sometimes, the relationship of the column length to the arch has a comparable proportion to the length of a body to its head. Figure 4 (Christ in Glory)

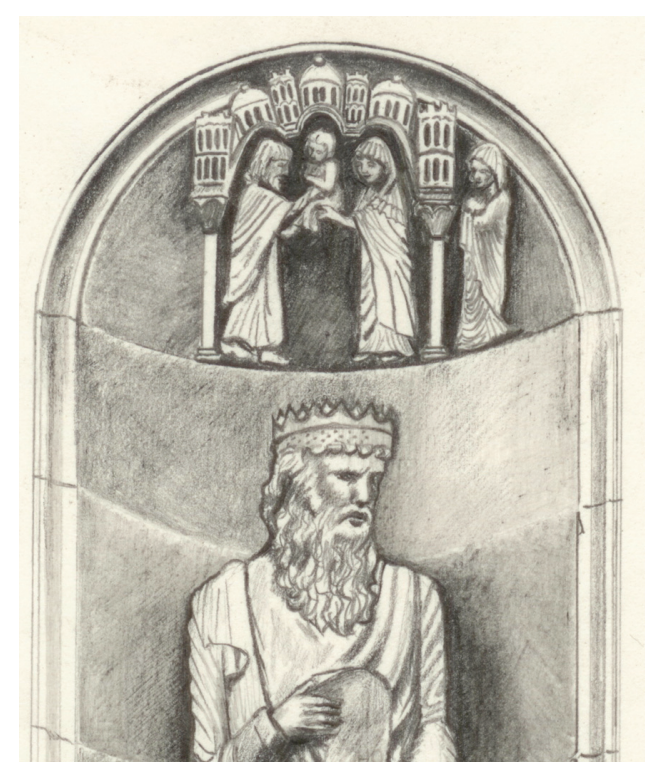

Figure 3: King David. Drawing by Cecilia Lewis Kausel, after a sculpture by Benedetto Antelami of the west façade of the Cathedral of Fidenza, circa 1180. 


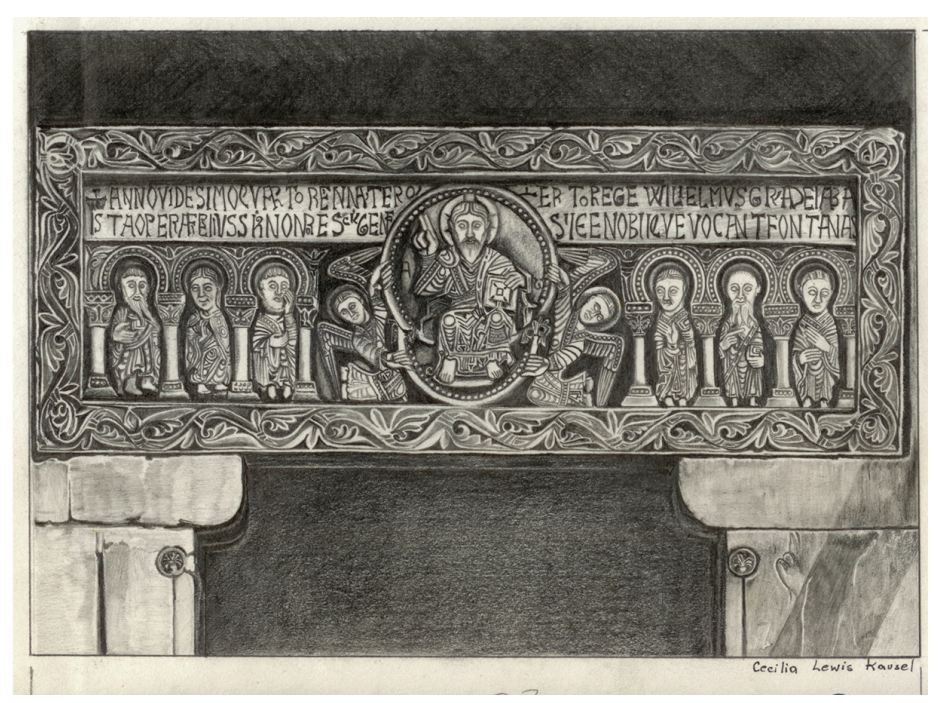

Figure 4: Christ in Glory bas relief at San Genis des Fontaines in France, 1019-1020. Drawing by Cecilia Lewis Kausel.

shows an artistic reproduction of San Genis des Fontaines in France. This theme depicts two angels carrying Christ who is accompanied by six of his apostles. The various arches become - in horseshoe fashion - narrower at the neck and are supported by columns that surround the trunk of the figures. Observe the distortion of the bodies tightly fitting the arches - a feature commonly found in medieval art - and how the figures appear subordinated to the form of the arch. While the process of carving the stone may be the root cause of this subordination (as the carving is calligraphic) the outcome of this bas relief still constitutes a clear ritualization of the sheltering role of architecture on the human figure. (Many medieval sculptural motifs were derived from theological literature considered sacred at the time, such as bibles [4, 9]. See books on medieval architectural art.)

The world of visual symbols is subjective and any one image may convey more than one meaning to different individuals. An archetypal representation of the womb is widely quoted as the symbol of concave forms in architecture and art since Carl Jung proposed it. Hence, repetitive motifs such as the scallop associated to the Madonna and Child may be interpreted as allusive to Mary's conception. (Portoghesi includes some thoughts about this and other symbolic associations of the scallop. The scallop shell is associated with a woman's sex and fecundity. The scallop has also biblical allegorical meanings, as representing the baptism of Christ and identifying him or the apostle James in medieval imagery. The scallop was in use in sculpted form in walls of ancient Greece. Torres Balbas in 'Nichos y Arcos Lobulados' [10] observed that when the shell was turned upside down the scalloped arch or lobed arch was possible.)

However, this need not be the only notion conveyed, nor may this notion be the primary one behind the representation of a scallop. First, we need to accept that the need for shelter in humans is as important an instinctive search as the archetype of the comfort of the womb, which is also a shelter. When it comes to representation in niches, it does not seem impossible that the shell - as a structure that provides cover - is what is meaningful. For example, there is a widespread usage in history of the scallop's shell in architectural space, in particular, in niches. This indicates (though does not prove) that the scallop may evoke the role it plays in nature and its associations related to 


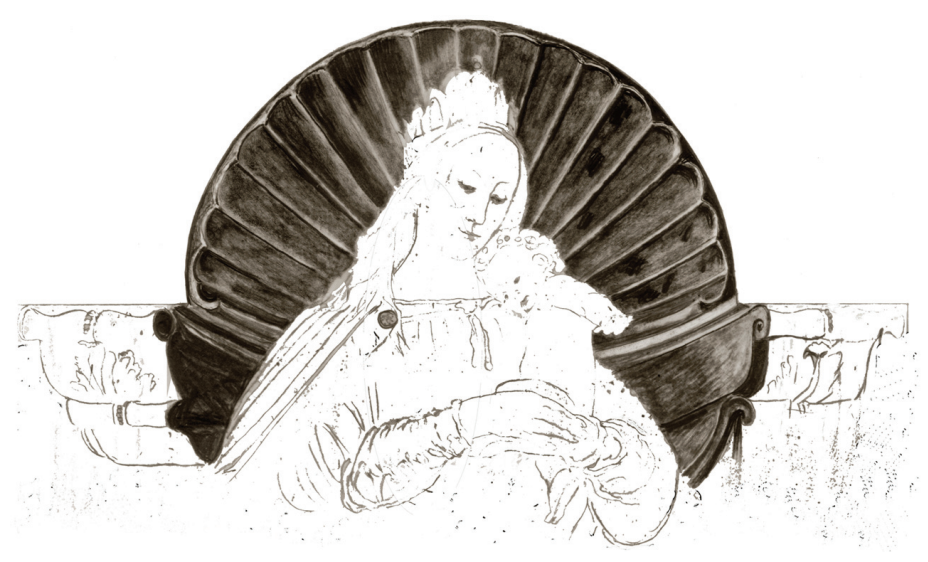

Figure 5: Shell in the painting of the Adoration with Donors by Hans Holbein the Younger, sketch by the author.

this role. In the Adoration with Donors by the German painter Hans Holbein the Younger (Fig. 5) he saw fit to include a shell within the scalloped arch in a niche behind the head of the Madonna and Child. Taking into account the fact that symbols can offer more than one meaning, in the specific evocation of the scallop by Holbein, this arch-shell, can be observed to have the form of the lower curves right and left (the scallop's wings) similar to a skull's curves under the brain. That such an interpretation may not be as tenuous as it may appear at first can be seen by observing that the modern words scallop, skull, and shell do all originate in the same old Scandinavian word skel [11]. There are other examples such as Early Georgian niches, where a head outlined by the scallop is depicted on the high part of the niche. This motif also shows reminiscences to the brain. Thus, more than a superfluous decoration, perhaps the scallop was incorporated in architectural interiors with a human figure as a celebration of the shell's natural form as an efficient structure in its role of rigid protection, just like the human skull.

Other examples of arched shapes that evoke the outline of the human form are presented in Fig. $6 \mathrm{a}$ and $\mathrm{b}$, which show ornamental details of Gothic arches. These illustrations come from a classical 19th century treatise by Warth on historic stone construction and detailing [12]. Figure 6a shows a Gothic cusped arch motif that evokes hooded monks. Figure $6 \mathrm{~b}$ shows some variation given by the narrowing of the figures, which suggests souls.

Arches, by the configuration of their pieces and curvature, allow masonry to span great spaces and circumvent the collapse of heavy masonry above an opening. Society commemorates the achievements of technology that enable and enhance life. As an ingenious structural element, the arch deserved to be celebrated in art for its amazing contribution to structures that have lasted millennia. And indeed it has been refined and its stones proportioned to look nice in the great works of architecture. Through representation, the arch soon belonged in both the functional mechanisms of mankind and the visual arts of craftsmen. How did the arch come to symbolize shelter? An influential factor must have been the aptness of its curvature as a compartment for the human figure. While the arch did not derive from the image of the human figure, it can be adapted to shape vaults, niches, and windows that follow the outline of the shoulders and the head. The complete suitability of arched doorways and windows with capitals and columns to outline the human form is important for the theme. 


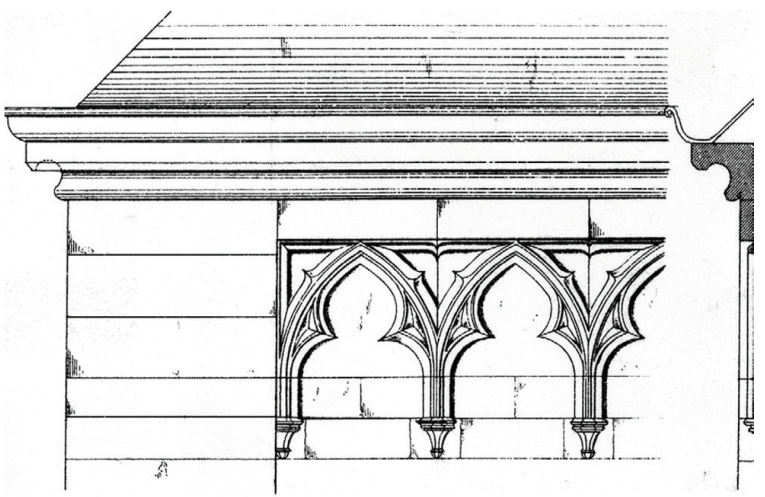

(a)

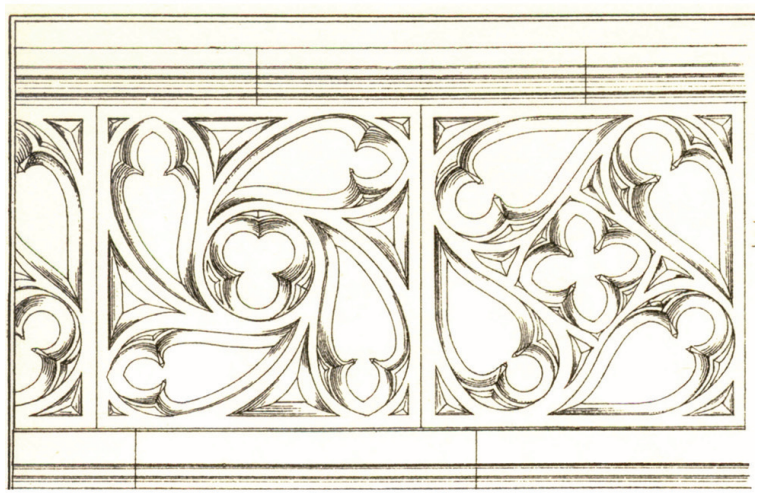

(b)

Figure 6: (a) and (b) Die Konstruktionen in Stein [12].

Figure 7 depicting La Communion $d u$ Chevalier at Reims Cathedral shows two cusped arches used in association and scale with the human form. The three-foil arch may be represented with or without the pointed tip. Figure 8, which is taken from the Cathedral of the Annuziazone in Portogruaro, Italy, shows ritualized three-foliated arches that surround human figures. On the left, the arch's space is completely filled by the nimbus and wings of the archangel Gabriel, and on the right by the halo of the Virgin.

In the Middle Ages, as cloisters and religious orders multiplied, identification of religious orders and ranks became necessary. The process included the development of religious dress and development of designs related to the liturgies. A number of religious items closely resemble architectural forms. The Miter in Fig. 9 illustrates the congruence between this object and the shape of a Gothic vault. When contemplated together, vault and bishop's miter seem to be related forms or a pair of harmonious and complementary designs (comparable to the theme of human figure and aedicule). While in the earlier times of Christianity, miters were not proportioned as Gothic naves, in due time, around the 12th century they converged with the vaults. Pictorial depictions of bishops show the tall miter proportion in 14th century paintings. The miter also enhances the height of the head which in 


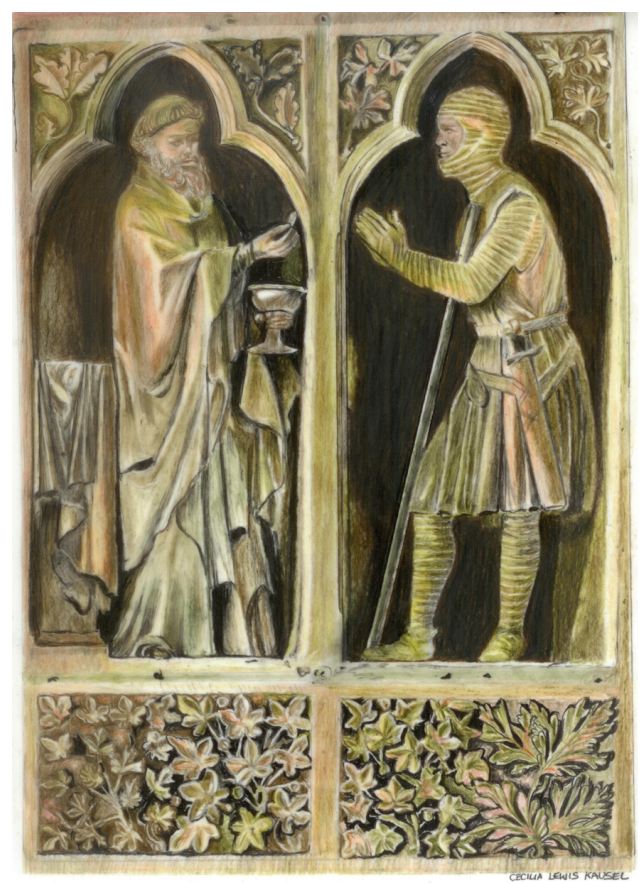

Figure 7: Cusped arches in La Communion du Chevalier at Reims Cathedral, 13th century. Drawing by Cecilia Lewis Kausel. The outline of the arches mimics the curve of the head and upper torso.

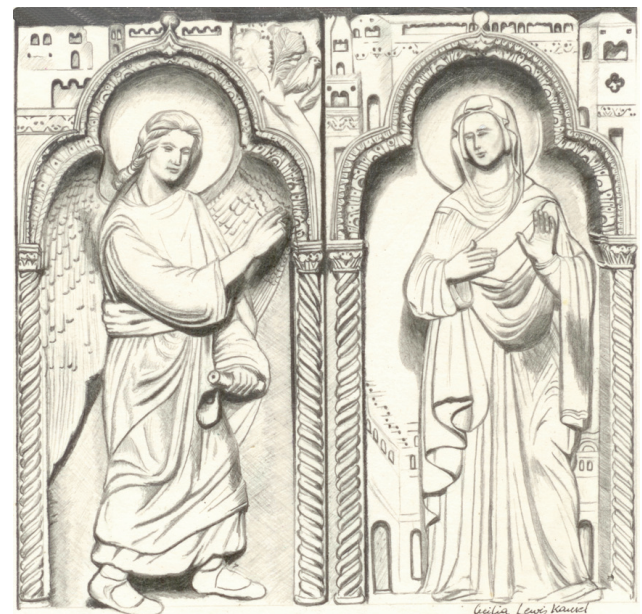

Figure 8: Sculptures in the Basilica of the Annunziazione, Portogruaro, end of 13th century. Drawing by Cecilia Lewis Kausel. 


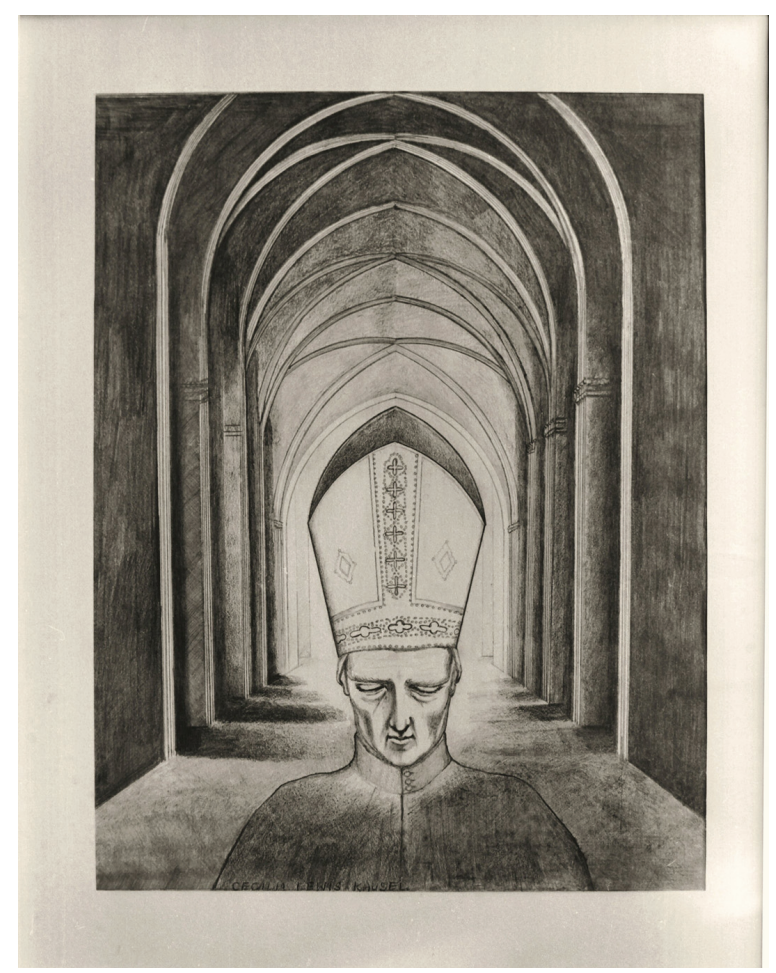

Figure 9: The Miter, by Cecilia Lewis Kausel, 1982.

turn enhances the supremacy of the higher rank of the prelate and also perhaps exalts his wisdom or judgment.

The Coffered Mantle in Fig. 10 shows a composite of a sculpture at the tomb of Richard Beauchamp in the Church of Saint Mary in Warwick, and a vertical cross-section of a generic, classical building found in Von Egle et al., 1905. This drawing is meant to illustrate the match between the coffered ceiling and the sculpture's mantle, as if the dome were a mortuary cover as well, and to show the close complementary forms of the dome and the head thus clothed. Many classical buildings were found suitable to provide a 'funerary' kind of aesthetics or association. While in this pair of designs, it is the mantle that approaches a dome's coffered spaces, a dome's coffering could also be perceived as reminiscent to regularized and stylized small concavities as in the interior of the cranium, especially the markings of a frontal lobe.

\section{THE VAULTS: COVER FOR THE INTELLECT}

Domes are comparable to the human head in that by being nearly spherical, they are shaped to best resist external forces. In the skull, this was achieved by the forces of nature and evolution, while in structural domes, it is the result of choices by builders. However, it is in vaults that details of innervations have appeared, or tiny arches that can evoke anatomical details more obviously than domes. (These statements do not mean to do away with any of the conscious symbolism attributed to domes 


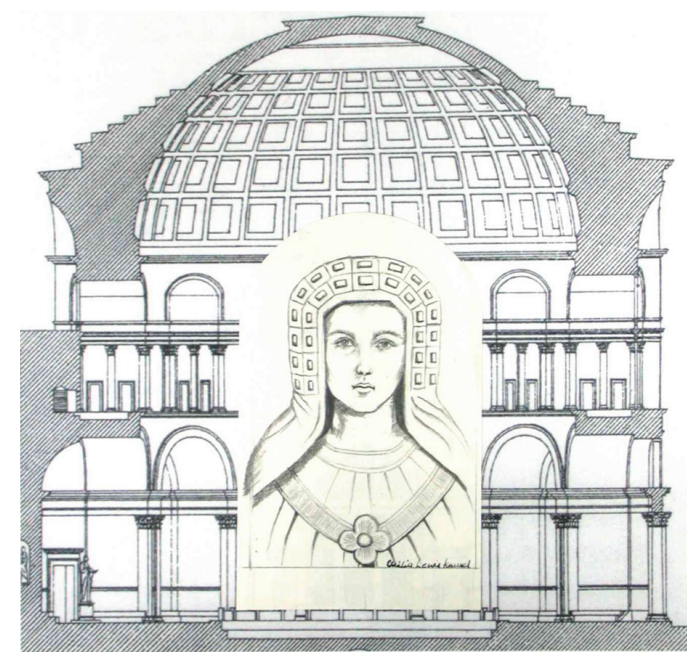

Figure 10: Coffered Mantle. Central portrait by Cecilia Lewis Kausel. The mantle for the central drawing comes from a sculpture in the tomb of Richard Beauchamp in the church of St. Mary, Warwick. The classical building in the background is from Baustil-und Bauformenlehre, Stuttgart, 1905, by Von Egel et al., reprinted in 1995 by Verlag Th, Schäffer, Hannover, p. 185 .

as the image of artifacts of culture can be endowed with multiple symbolic messages [1, 3]). Contemplation of images of these vaults in the context of the brain may indeed tell more than words ever could.

As a first example, consider Figs 11 and 12, which show, respectively, the choir and cloisters of Gloucester Cathedral in thematic relationship with the mind. The fan vaulting in these structures evokes the fanning of the temporalis muscle and its markings on the skull; the branches recall arteries and nerves as they fan out on both sides of the brain; the line of central decorative patterns evokes the longitudinal cerebral fissure between the two brain hemispheres; and the space at the center of four flanking fan vaults recall the fontanel in infants. It is clear that fan vaults and other similar structures may not be found analogous solely to ramifications in the brain; for example, Marc Antoine Laugier's remarkable Essai sur l'architecture (1753) depicts a primitive wooden hut with its roof formed by the branches of several closely spaced trees, and this origin is usually associated to the 'branching' designs of Gothic vaults. It would appear, however, that the overall organization of fan vaulting with top roundels and branching better approaches the patterns of the membranes covering the brain which is the seat of the intellect. An additional eschatological meaning that is discerned in the cloisters (Fig. 12) seems to be the rising of souls of monks to heaven which culminate in a formation evoking a greater mind, possibly the creator's. A hierarchical upward succession of souls was a very common vision of the medieval imagination, which is observed in pictorial representation.

Figure 13 depicts Dura Mater, an imaginary design by the author showing an arched doorway that follows the contour of the brain. For simplicity, the system is shown in cut stone covered by a cast molded after a section of a brain. Clearly, an arch of this kind does not exist anywhere, but it could be regarded as very similar to a lobed horse-shoe arch of Spain and Islamic Africa. These arches have a number of curved projections, and they too recall a complementary outline of the brain (see Figs 14 and 15). The remarkable similarity of the arch designed after the outline of the brain by the 


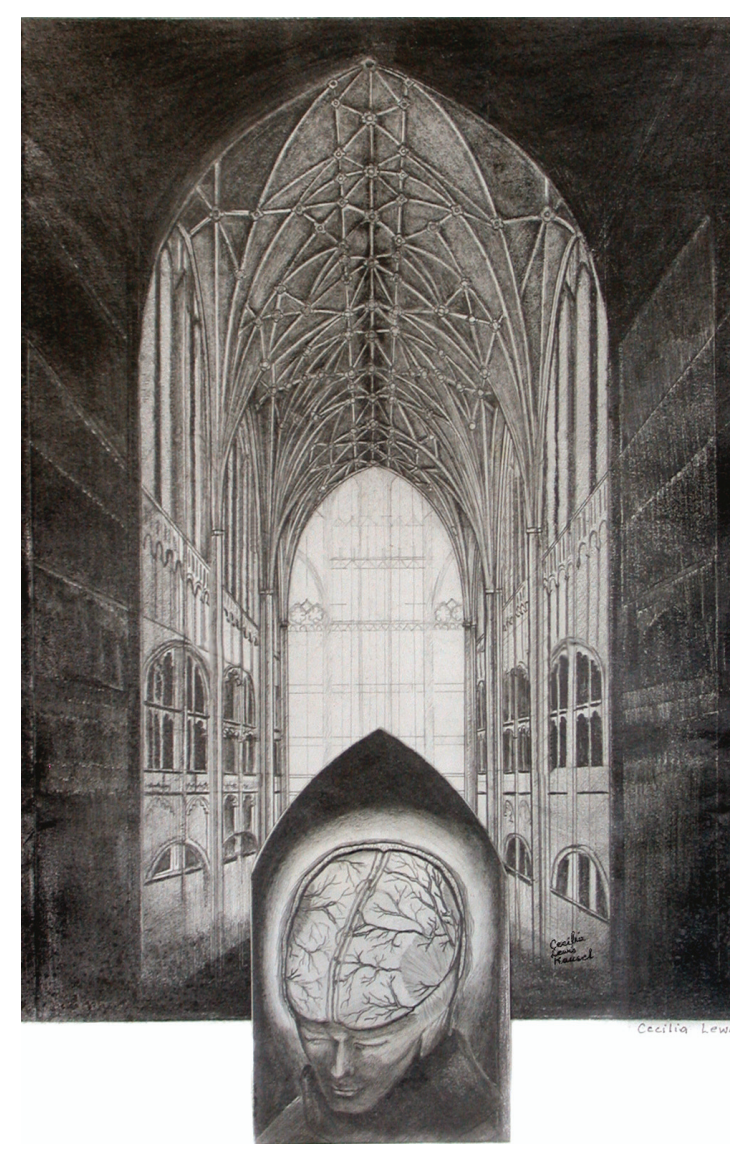

Figure 11: Cathedral Nave. Original hand sketch by Cecilia Lewis Kausel. Inspired by the Gothic nave of Gloucester cathedral, 1985, after an original diagram of parallel made in 1977. Published in Fall 1987 in the Journal of IFRAA.

author and the outline of the lobed horse-shoe arch is not likely to be coincidental. The lobed arch is sometimes referred to as a scalloped arch.

A variation is the slightly pointed arch decorated with mocarabes or mukarnas (also termed Almocarbe and Almocarabe [13]). These are profuse adornments consisting of a succession of tiny arches. An interesting example is the vaulting of the Moroccan Friday Mosque in Fig. 16. (Other famous vaults decorated with mocarabes in the manner of stalactites are the well-known Sala de las Dos Hermanas and the Sala de Reyes at the Alhambra. Their outline also recalls the top of the nimbus of the Prophet Muhamad in a painting where he is shown riding on the Buraq on his journey to paradise, of later centuries.) The fragile elongated elements that project down at the junction of two tiny horseshoe-shaped arches in the mocarabe unit remind of the sulci (furrows or convolutions) in the brain.

This is not to say that the brain may have been the direct motif for the design of the mocarabe. The mocarabe arises from a small unit of tiny arches, and in terms of its overall design effect, inspirations 


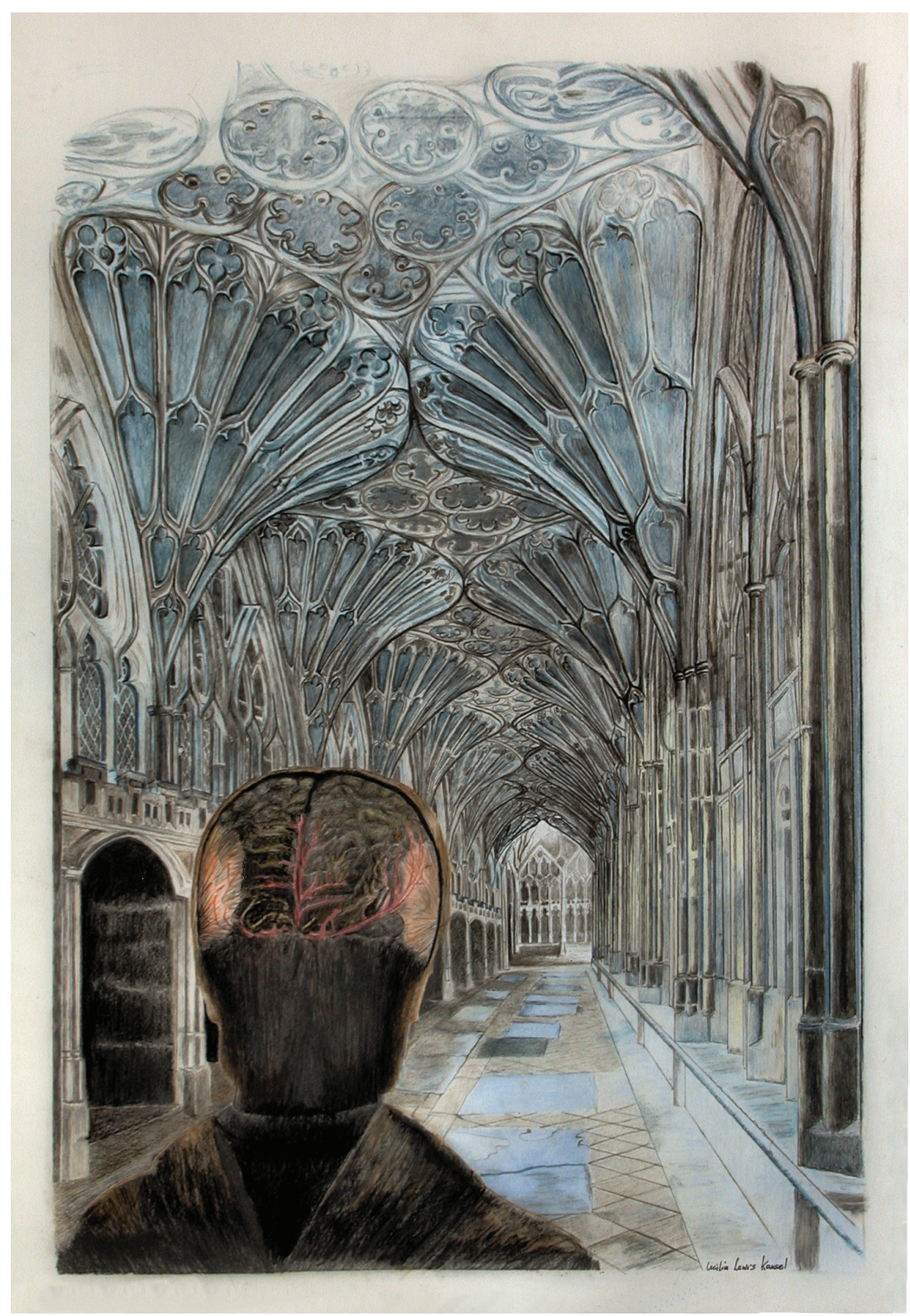

Figure 12: The Cloisters. Original drawing by Cecilia Lewis Kausel of the Gloucester Cathedral cloisters.

may be found possibly in things such as leaves, lace, stalactites, or traced back to Oriental rug designs. Nonetheless, the organization of the composition, with multiple concavities ending in thin and fragile, structurally unnecessary protrusions, and the rhythm of the lobed spaces, exhibit a striking similarity to a stylized or regularized surface of the brain, and this analogy may have provided a 


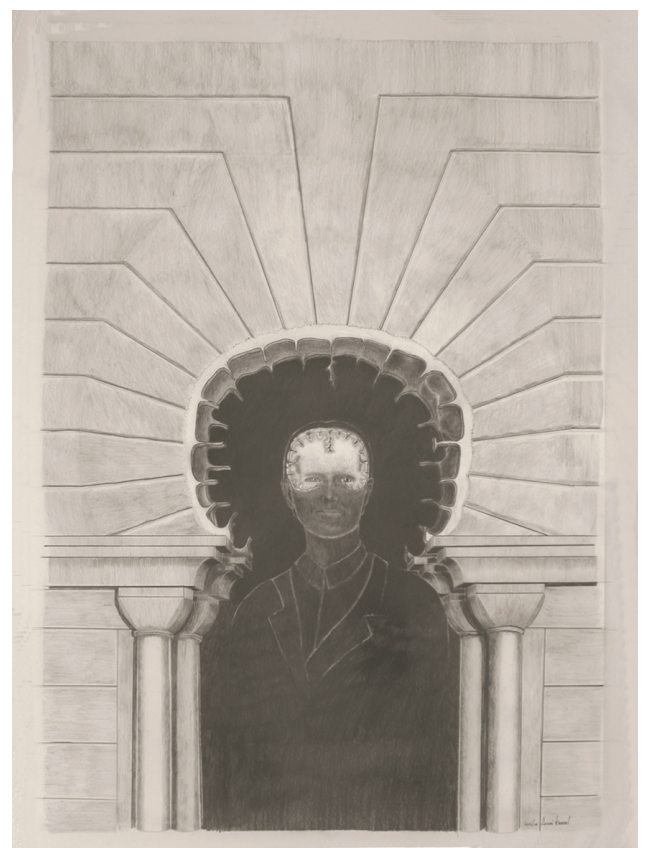

Figure 13: Dura Mater. Original design and drawing by Cecilia Lewis Kausel.

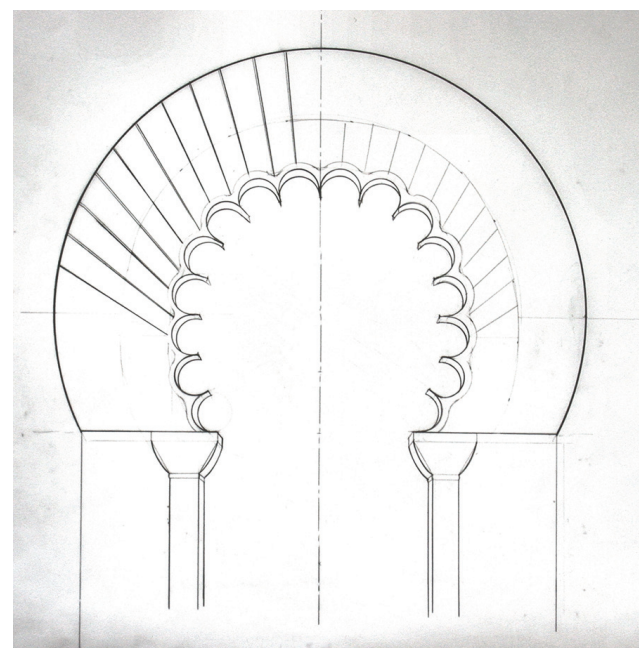

Figure 14: A Lobed Arch. Diagram by Cecilia Lewis Kausel.

subtle, even if subconscious, template for the design of these elaborate vaults. And what greater symbol than the seat of the mind could have provided a better source of inspiration to the design of these significant vaults in history in buildings that were intended to provide shelter for body and spirit? 


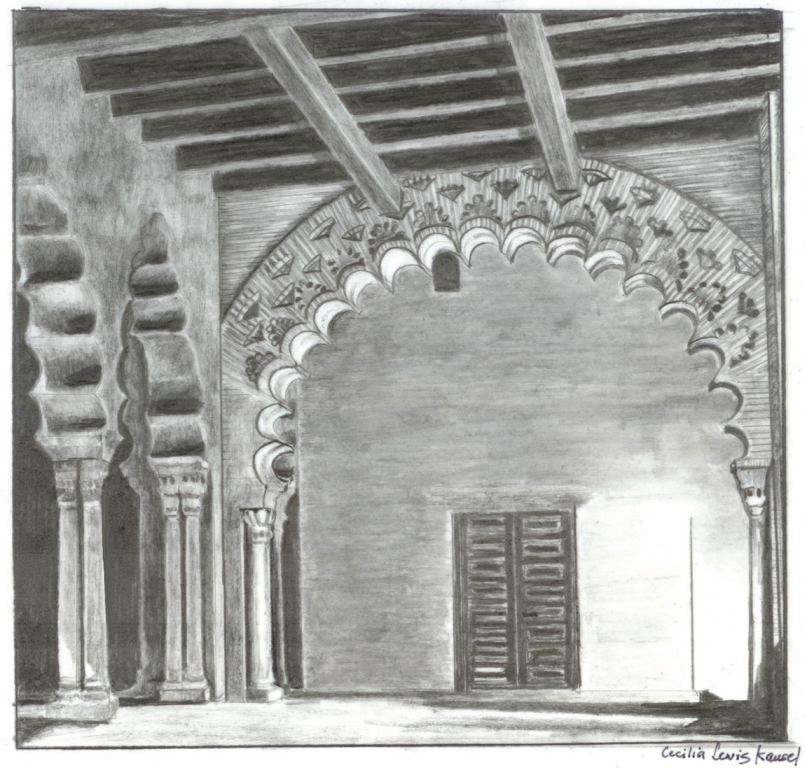

Figure 15: Aljaferia Mosque. Hand sketch by Cecilia Lewis Kausel of the lobed or scalloped arches of the Alfjaferiya Mosque in Zaragossa, Spain.

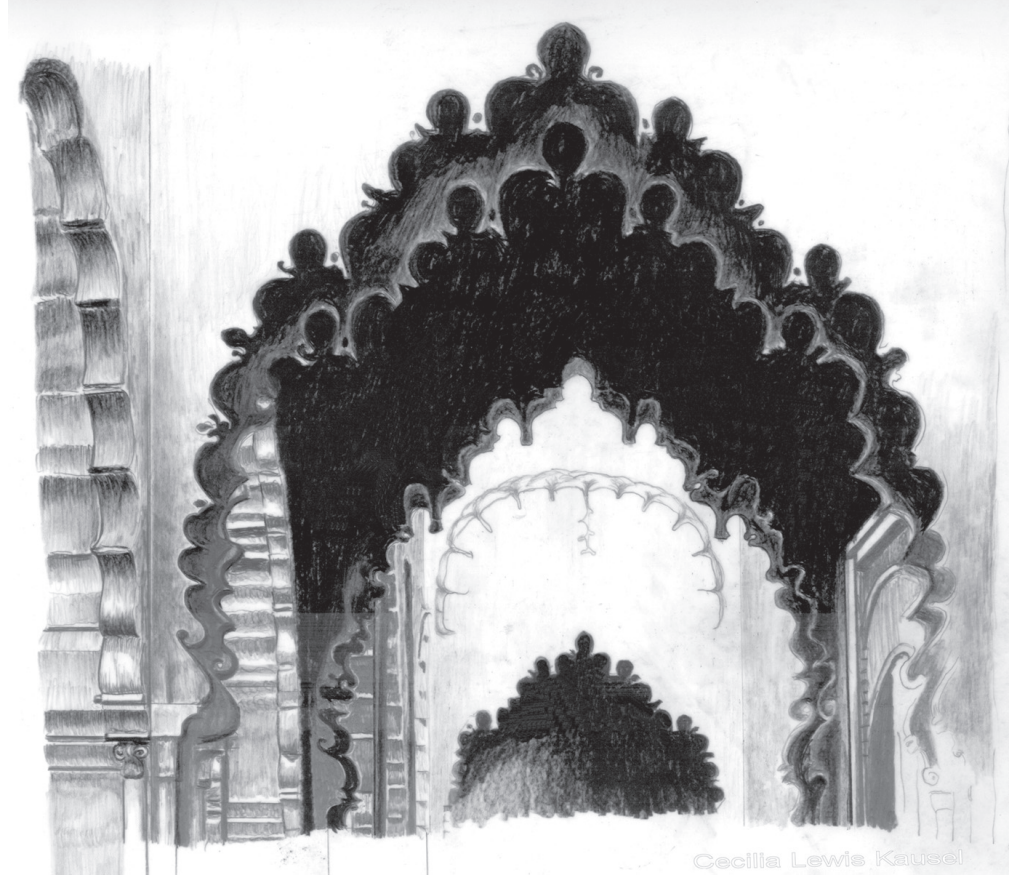

Figure 16: Drawing of the vaults of the Moroccan Friday Mosque, by Cecilia Lewis Kausel. 


\section{CONCLUSION}

The central idea taken up in this article advances the thought that some greater design theme evoking the upper human figure subtly expressed may be recognized in vaulted and domed architecture, and that this theme provides power to the design composition of these structures. The human-like recollection in the arch, vault, and dome can also be discerned in the smaller contexts of niches, doorways, windows, and funerary constructions. If we consider the blind process of approximating subconscious forms like the surfaces of the brain and putting them in the context of the material used in building, and the process of regularizing the design elements into an organized composition, the comparable features are remarkable. The creative process thus can leave an imprint of a complementary outline of the head and torso, and sometimes an imprint of a complementary surface of the brain. The brain's recollection may reflect the reach of the human intellect, and in a religious context perhaps 'the mind of God'. This constitutes a great symbol - perhaps the greatest - of a constructed container destined to provide cover. This evocation does not seem to be dependent on the materials used, on the concept planned, or even the methods applied.

In closing, it is in the smaller ritualized examples of architectural imagery that we can begin to comprehend the relationships of form-giving and the culture's assimilation of designs. The reason for this is that the objects can more easily be distorted and adapted than large-scale vaults. In these miniaturized representations, the metaphor of a natural cover for mankind in the manner of an exoskeleton arises more explicitly. By comparison, in structural vaults, the scale is too vast in comparison to the human scale and the imprint of a brain thus impacts rather as a theme that celebrates the intellectual effort that designed an astonishing achievement: the vault.

While natural forms are true to nature, man-made designs usually undergo consideration as to their optimum shape. Within the long development of styles in human society it can be said that there is a search of what is the right design of constructed things. Architectural imagery is a source of inspiration for interiors and other decoration since very ancient times. However, the form, parts, and proportions of small objects such as chests - meant to keep valuables like relics or jewelry - are different from those of buildings, but these objects may include structural elements such as columns, arches, roof tops, or tracery, which serve purely decorative purposes, and have no structural function. When architecture (structural in origin) is used by a craftsman in smaller objects and furniture, it is intended to suggest either the noble or sacred function of a grandiose building, or its status and elegance. It also attempts to convey the idea that the piece does what buildings do: to keep and protect within. On the other hand, architectural décor in furniture pieces is often meant to harmonize with the style of people's houses, for elegance and quality in overall design. Hence, all these architectural forms are used somewhat as a visual language, to communicate the notions of buildings. And in the cultural activity of ritualizing the famous constructions of technology, building parts once meant for structural support cease to serve such function. These are all conscious goals and customs as opposed to the unintended parallelism of the human outline and brain with some vaults observed in this article. This frees the craftsman - who probably never designed a building - to create images of structural objects without the constraints of structural mechanics, allowing him to morph and stylize structural elements in the object at will. This phenomenon seems key to the understanding of the various relationships of form-giving and cultural assimilation, and appreciation of forms as the precious objects we create hold understanding of our cultural psyche.

\section{REFERENCES}

[1] Lewis Kausel, C. The fundamental expression of an architectural motif, SM Thesis, Department of Architecture, Massachusetts Institute of Technology, 1982. 
[2] Mallgrave, H.F., Gottfried Semper: Architect of the Nineteenth Century, Yale University Press: New Haven, 1996.

[3] Lewis Kausel, C., The image of architecture in objects. Journal of the Interfaith Forum of Religion, Art and Architecture, 1, 1986.

[4] Yarza Luaces, J., Arte y Arquitectura en España: 500-1250, 1979.

[5] Jairazbhoy, R.A., An Outline of Islamic Architecture, Oxford University Press: Karachi, Pakistan, 2003.

[6] Lewis Kausel, C. \& Julian, A.P., eds, Santiago Calatrava, Conversations with Students, The MIT lectures, Princeton Architectural Press: New York, 2002.

[7] Portoghesi, P., Natura e Archittetura, Skira editore: Milano, 1999.

[8] Burgess, S.C. \& King, A.M., The application of animal forms in automotive styling. The Design Journal, 7(3), pp. 41-52, 2005.

[9] Male, E., Medieval iconography. The Gothic Image: Religious Art in the Thirteenth Century, 1918.

[10] Torres Balbás, L., Nichos y Arcos Lobulados. Al-Andalús, 1956.

[11] American Heritage Dictionary, Appendix I, Indo-European roots.

[12] Warth, O., Die Konstruktionen in Stein, J.M. Gephard's Verlag, Leipzig, reprinted in 1993 by Verlag Th. Schaeffer, Hannover, 1903.

[13] Nuere, E., La Carpintería de Armar Española, Instituto de Conservación y Restauración de Bienes Culturales (ICRBC): Madrid, Spain, 1989. 